ARTIGO

\title{
APORTES DEL TRABAJO SOCIAL COLOMBIANO A LA EDUCACIÓN POPULAR CON IDOSOS(AS) EN LA AMAZONÍA BRASILEÑA
}

\author{
JUANITA MERCHÁN PÉREZ ${ }^{1}$ \\ ORCID: https://orcid.org/0000-0002-5299-2166 \\ JOÃO COLARES DA MOTA NETO² \\ ORCID: https://orcid.org/0000-0003-3346-1885
}

\begin{abstract}
RESÚMEN: Este artículo es resultado de una Investigación-Acción Participativa realizada durante una pasantía profesional de Trabajo Social de la Universidad Nacional de Colombia en las actividades pedagógicas del Núcleo de Educação Popular Paulo Freire de la Universidade do Estado do Pará, en una Instituição de longa permanência para idosos (ILPI) en la ciudad de Belém-Brasil. Tiene como objetivo reflexionar críticamente y dar a conocer los aportes teórico-metodológicos que se realizaron desde el Trabajo Social Colombiano a la Educación Popular con Idosos(as) en la ciudad de Belém-Brasil. Para ello, se exponen las metodologías y técnicas participativas (la cartografía social y el árbol de problemas) como un diálogo transdisciplinar entre el Trabajo Social Colombiano y la Educación Popular que permite que se fomenten escenarios de concientización popular con personas de la tercera edad de Belém. Los resultados actualizan el debate sobre la Educación Popular y la Investigación-Acción Participativa, evidenciando su vigencia junto a un segmento poblacional poco investigado en los estudios educacionales, las y los idosos tutelados por el Estado.
\end{abstract}

Palabras clave: Trabajo Social, Educación Popular, Investigación-Acción Participación, Árbol de Problemas, Cartografía Social.

\section{CONTRIBUTIONS OF COLOMBIAN SOCIAL WORK TO POPULAR EDUCATION WITH THE OLDER ADULTS IN THE BRAZILIAN AMAZON}

\begin{abstract}
This article is the result of a Participatory Action Research carried out during a professional internship in Social Work at Universidad Nacional de Colombia, in the pedagogical activities of the Núcleo de Educação Popular Paulo Freire of the Universidade do Estado do Pará at a long-term institution for older adults (ILPI - Instituição de longa permanência para idosos) in the city of BelémBrazil. It aims to critically reflect and socialize the theoretical and methodological contributions made in the Colombian Social Service to the Popular Education with Older Adults in the city of Belém-Brazil. To this end, participatory methodologies and techniques (social cartography and the problem tree) are
\end{abstract}

\footnotetext{
${ }^{1}$ Universidad Nacional de Colombia. Bogotá, Colômbia. <jmerchanp@unal.edu.co>

2 Universidade do Estado do Pará. Belém, PA, Brasil.<joaocolares@uepa.br> Educação em Revista|Belo Horizonte|v.37|e233148|2021
} 
exposed as a transdisciplinary dialogue between Colombian Social Work and Popular Education, which allows the creation of scenarios of popular awareness with older adults of Belém. The results update the debate on Popular Education and Participatory Action Research, evidencing its validity together with a population segment little investigated in educational studies, the older adults protected by the State.

Keywords: Social Work, Popular Education, Participative Action Research, Problem Tree, Social Cartography.

\section{CONTRIBUIÇÕES DO TRABALHO SOCIAL COLOMBIANO À EDUCAÇÃO POPULAR COM IDOSOS(AS) NA AMAZÔNIA BRASILEIRA}

RESUMO: Este artigo é resultado de uma Investigação-Ação Participativa realizada durante um estágio profissional de Serviço Social da Universidad Nacional de Colombia nas atividades pedagógicas do Núcleo de Educação Popular Paulo Freire da Universidade do Estado do Pará em uma Instituição de longa permanência para idosos (ILPI) na cidade de Belém-Brasil. Tem como objetivo refletir criticamente e socializar os aportes teórico-metodológicos que se realizaram a partir do Serviço Social Colombiano à Educação Popular com Idosos(as) na cidade de Belém-Brasil. Para tanto, expõem-se as metodologias e técnicas participativas (a cartografia social e a árvore de problemas) como um diálogo transdisciplinar entre o Serviço Social Colombiano e a Educação Popular, que permite que se formem cenários de conscientização popular com pessoas da terceira idade de Belém. Os resultados atualizam o debate sobre a Educação Popular e a Investigação-Ação Participativa, evidenciando sua vigência junto a um segmento populacional pouco investigado nos estudos educacionais, os idosos tutelados pelo Estado.

Palavras-chave: Serviço Social, Educação Popular, Investigação-Ação Participativa, Árvore de Problemas, Cartografia Social. 


\title{
INTRODUCCIÓN
}

\author{
Eu sópeço a Deus \\ Que a dor não me seja indiferente \\ Que a morte não me encontre um dia \\ Solitário sem ter feito o que en queria
}

Que ocho personas posean la misma riqueza que la mitad más pobre de la humanidad ${ }^{4}$, eso es injusto; que los ricos sean cada vez más ricos y los pobres sean más y más pobres, eso es injusto; que los niños y niñas pobres tengan el doble de probabilidad de morir antes de los 5 años, y que tengan el doble de la tasa de desnutrición entre menores de 5 años, eso es injusto; que las niñas tengan seis veces más probabilidad de mantenerse fuera de la escuela, y que en la edad adulta tengan 10\% menos remuneración que los hombres, eso es injusto ${ }^{5}$. Cada privación, resultado de una cuestión de género, de clase, raza o de etnia exacerba el efecto de las otras (UNICEF, 2016) pero...¿cuándo coinciden dos o más?.

Hay condiciones reales, de opresión y desigualdad que se viven a diario, que están llenas de dolor, de angustia, de desespero, de tristeza y desesperanza. Estas situaciones y condiciones son un factor importante en el desarrollo de cada persona. Sin embargo, como afirma Paulo Freire (2006), somos seres condicionados - por cuestiones genéticas, sociales, históricas, de clase y de género; dichos condicionamientos nos marcan y desde ellos nos referimos, pero no somos determinados por ellos. Estas condiciones no determinan a las personas, no hay un destino ya señalado; hay una posibilidad de transformación, hay posibilidad de un mundo más humano y más justo, y es por ello que existen campos del conocimiento cómo el Trabajo Social y la Educación Popular.

Esa posibilidad de transformación social, Paulo Freire la expone a lo largo de su vida, y por medio de sus obras propone un ejercicio serio y comprometido de concientización popular desde la educación. Esta apuesta ético-política por la transformación social se basa en la concientización de los oprimidos; sujetos "objetivo" de la Educación Popular y el Trabajo social.

El Trabajo Social debe responder a las demandas legítimas y a los derechos reconocidos de los sujetos, familias, grupos y comunidades, en especial de los sectores vulnerables; a su vez, se debe promover procesos de transformación y construcción de tejido social (CONETS, 2015).

El Trabajo Social promueve la defensa de los Derechos Humanos y la dignidad, así que este trabajo se fundamentó en el Estatuto do Idoso (BRASIL, 2003) ${ }^{6}$ de Brasil, que promueve y promociona los derechos fundamentales. El trabajo del Núcleo de Educação Popular Paulo Freire (NEP), de la Universidade do Estado do Pará (UEPA), se ubica en el derecho a la educación (Art. 20), en el que "O idoso tem direito à educação, cultura, esporte, lazer, diversões, espetáculos, produtos e serviços que respeitem sua peculiar condição de idade" (BRASIL, 2003, p.18).

El presente artículo y el proceso que relata responden al compromiso personal y profesional de los autores y el NEP por un trabajo hacia la vida digna de los grupos sociales más vulnerados. Parte de la idea de que:

A dimensão política do projeto ético-político do serviço social se posiciona a favor da equidade e da justiça social, na perspectiva da universalização do acesso a bens e a serviços relativos às políticas e programas sociais; a ampliação e a consolidação da cidadania são explicitamente postas

\footnotetext{
${ }^{3}$ Mercedes Sosa e Beth Carvalho (2011). Eu só peço a Deus.

${ }^{4}$ OXFAM (2017). Ocho personas poseen la misma riqueza que la mitad más pobre de la bumanidad. Recuperado el 20 de mayo de 2018 , de: https://www.oxfam.org/es/sala-de-prensa/notas-de-prensa/2017-01-16/ocho-personas-poseen-la-misma-riqueza-quela-mitad-mas

5 Tomado de: Pictoline (2016). Recuperado el 20 de Mayo de 2018 de : http://pictoline.com/?s=desigualdad

6 “A Política Nacional do Idoso (PNI), Instituída pela Lei $\mathrm{n}^{\circ}$ 8.842, de 4 de janeiro de 1994, regulamentada pelo Decreto $\mathrm{n}^{\circ}$ 1.948, de 3 de julho de 1996, e o Estatuto do Idoso, lei no 10.741/2003, regulamentam os direitos assegurados às pessoas com idade igual ou superior a 60 anos. O Estatuto do Idoso é destinado a regular os direitos assegurados às pessoas com idade igual ou superior a 60 anos".
} 
como garantia dos direitos civis, políticos e sociais das classes trabalhadoras (NETTO, 2006. p. 16).

De esta manera, el siguiente artículo pretende exponer que las metodologías y técnicas participativas (la cartografía social y el árbol de problemas) consiguen un diálogo transdisciplinar entre el Trabajo Social Colombiano y la Educación Popular que permite que se fomenten escenarios de concientización popular en poblaciones vulnerables, como las personas de la tercera edad - en adelante $\operatorname{Idosos}(\mathrm{as})^{7}$ - de una Instituição de longa permanência para idosos (en adelante ILPI) en Belém.

\section{CONTEXTO DE LA EDUCACIÓN POPULAR CON IDOSOS}

\section{E1 NEP: Núcleo de Educacão Popular Paulo Freire}

El Núcleo de Educacão Popular Paulo Freire (NEP) es un grupo de enseñanza, investigación y extensión de la Universidade do Estado do Pará (UEPA), conformado por estudiantes (de pregrado y posgrado) y profesores vinculados a la UEPA. Nació en el año 1995 por medio de la iniciativa estudiantil PROALTO $^{8}$ y a partir del 2002 se constituyó como NEP.

El NEP fundamenta su práctica educativa popular en la filosofía (ético-política) y en los presupuestos teórico-metodológicos freireanos, actualmente está afiliado al Consejo de Educación Popular de América Latina y el Caribe (CEAAL). Desarrolla sus actividades dentro y fuera de la UEPA, como en escuelas, ILPI, hospitales, centros de asistencia social, comunidades urbanas y rurales.

Este grupo "desenvolve ações educativas com diversos segmentos sociais vinculados às classes populares: crianças, jovens, adultos e idosos, em diferentes instituições: hospitais, centros comunitários, asilos e escolas. Esse trabalho educacional dimensiona-se como uma pedagogia social, que considera integrar suas ações educativas com as comunidades hospitalares e periféricas, sendo os espaços não escolares compreendidos como espaços de educação inclusiva e de participação popular" (MOTA NETO; OLIVEIRA, 2017, p.24).

El NEP se basa en el diálogo, la humanización, la pregunta, la amorosidad, el respeto a la oralidad, la praxis, la criticidad, la acción a partir de los temas generadores, y la utilización de situaciones variadas de aprendizaje, como presupuestos pedagógicos. En la actualidad el NEP tiene diversas líneas de investigación y está constituido por los siguientes grupos de trabajo:

1. Banco de Leite: cuyo trabajo educativo va dirigido a la alfabetización a madres y padres de niños y niñas internados en un hospital público de Belém.

2. Brinquedoteca $\&$ Casa de Apoio: en el que se trabaja con niños, niñas, jóvenes, y mujeres de un albergue para personas del interior del estado que van a Belém a hacer tratamiento médico durante un periodo largo de tiempo en hospitales públicos. Su accionar es de carácter pedagógico y psicológico con niños, niñas, mujeres, jóvenes y adultos en este ambiente hospitalario.

3. Grupo de Educação Especial: desarrolla un trabajo pedagógico con educandos con discapacidad cognitiva en varias escuelas pública de Belém.

4. Grupo de Estudos e Trabalhos em Filosofia Freiriana: trabaja desde el 2007 la enseñanza de filosofía con niños y niñas.

5. Instituição de Longa Permanência para Idosos: Es un espacio en el que se trabaja con una perspectiva freiriana círculos de palabra, lecturas y producciones basadas en las realidades de las y los idosos tutelados por el Estado.

La Instituição de Longa Permanência para Idosos-ILPI- es una institución ${ }^{9}$ para adultos mayores en Belém-Pará. Actualmente acoge a 38 personas mayores, con situaciones de vulnerabilidad y

\footnotetext{
${ }^{7}$ Persona de la tercera edad en lengua portuguesa.

8 Programa de Alfabetização de Jovens e Adultos: Processo social para libertação (PROALTO).

${ }^{9}$ Regido por el capítulo II del Estatuto del Anciano, Ley Federal no 10.741 de 01 de octubre de 2003. Educação em Revista|Belo Horizonte|v.37|e233148|2021
} 
riesgo social, por lo general con bajo nivel socio económico, con edades entre 60 a 100 años de edad y sin una red de apoyo; son personas entre hombres y mujeres, dependientes y semidependientes a nivel físico y económico. Este hogar dispone de un equipo interdisciplinar de fisioterapeutas, terapeutas ocupacionales, enfermeros y trabajadoras sociales que dan asistencia especializada a las y los idosos.

El NEP desenvuelve sus actividades pedagógicas en el ILPI desde 2006, con un trabajo en el que la palabra y el diálogo son los principales protagonistas. Durante estos años se han desarrollado investigaciones y trabajos de grado y maestría en los que las y los idosos son protagonistas de los procesos de producción del conocimiento, como la investigación participativa de Milene Leal (2017) sobre la trayectoria educativa escolar de las y los idosos a partir de sus memorias.

Igual que con los niños, lograr la atención con las y los idosos por largo tiempo es todo un reto pedagógico, sus pensamientos son a corto plazo y se olvidan con facilidad la cosas. Desde el NEP se venían desarrollando círculos de palabra acerca del territorio, las tradiciones, los alimentos, y la memoria, todos los martes en horario de 9:00h a 11:00h de la mañana. Para continuar con la temática y a su vez identificar los temas generadores para el trabajo anual del NEP en la institución, se optó por hacer un ejercicio de lectura y análisis de realidades con las y los idosos, a través de la cartografía social y el árbol de problemas, sustentados en la Investigación-Acción Participativa (IAP) como metodología.

Estas técnicas fueron propuestas y dialogadas con las pedagogas/educadoras populares del NEP, reconociendo el valioso saber que ya tenían consigo: a las y los idosos de la ILPI les gusta hablar de su pasado, sus gustos, sus historias, su Belém y todo el bagaje cultural que este significa. Les gusta sentirse realmente escuchados, observados y reconocidos como sujetos que cargan consigo historias interesantes, viajes increíbles, y una vida que importa. Por ello, se propusieron técnicas que incitaran el recuerdo con un sentido específico, lograr una conciencia de sí, y de un "nosotros", experiencias de vida particulares cargadas de una vivencia en común: ser idoso/a en el ILP.

\section{APROXIMACIÓN CONCEPTUAL}

\section{Trabajo Social: por los derechos humanos y la justicia social}

El Trabajo Social colombiano se concibe bajo dos dimensiones epistemológicas, en las que se desenvuelve y define; la dimensión profesional y la dimensión disciplinar. En su dimensión profesional, el Trabajo Social es una práctica social que busca intervenir los problemas sociales, evidenciados en el sufrimiento humano o estados-situaciones desfavorables para la dignidad humana; y en la dimensión disciplinar, el Trabajo Social es una práctica de investigación centrada en la producción teórica acerca de problemáticas sociales (MALAGÓN, 2012).

Un problema social es en principio una cuestión ética dado que la idea de problema remite a un indeseable social que implica carencia o sufrimiento. "Por esta razón todo problema social implica un juicio de valor negativo, es decir un enunciado que pone de presente la maldad en cualquiera de sus expresiones: la infamia, la injusticia, la inequidad, el desamor, la insolidaridad, la violencia" (MALAGÓN, 2003, p.19).

Esto, va íntimamente ligado a una cuestión de derechos humanos en tanto que se habla de condiciones dignas de vida, y el Trabajo Social le apuesta a una acción ética basada en la perspectiva de lo humano digno, la calidad de vida, la salud integral, el desarrollo y la felicidad

Así las cosas, el Trabajo social es una profesión-disciplina que analiza, estudia e interviene problemáticas sociales, evidenciadas en la pobreza, el sufrimiento, la desigualdad, e infinidad de situaciones que degradan la condición humana. Estas son situaciones y condiciones concretas (de género, clase, raza, edad, orientación sexual, entre otras) que influyen de forma importante en la vida de cada persona, sin embargo - como se decía anteriormente - no las determina; por ello el Trabajo Social - y la Educación Popular - tiene un carácter social ético, político y crítico, porque trabaja con personas que viven situaciones de deshumanización, pobreza, discriminación, sufrimiento y busca la garantía de sus derechos y la justicia social. 
El Trabajo Social se desarrolla en el ámbito de las interacciones entre los sujetos, las instituciones, las organizaciones sociales y el Estado, de manera dialógica y crítica. Comporta referentes de intervención que se constituyen en el eje que estructura el ejercicio profesional, confiriéndole un sentido social y político para potenciar procesos de transformación social (CONETS, 2015, p. 22).

El Trabajo Social aplica la investigación e intervención de forma articulada, no puede haber una intervención sin investigación, ni investigación sin intervención social. Es la profesión que se caracteriza por hacer análisis de contexto con una lectura profunda y crítica de la realidad y al mismo tiempo proporciona herramientas para la transformación a nivel micro: en procesos como los de Educación Popular con idosos(as), o a nivel macro: como en la formulación, ejecución y evaluación de servicios, planes, programas, proyectos y políticas sociales que apuntan a la preservación, y defensa de los Derechos Humanos y la justicia social.

El ser del Trabajo Social configura, por una parte, el reconocimiento del "otro" y de "los otros" como sujetos sociales y políticos capaces de transformar realidades sociales en los procesos de formación, participación, movilización y acción colectiva; y, por otra parte, el reconocimiento de las condiciones estructurales y coyunturales de las realidades sociales en la que los mismos sujetos, las organizaciones, las instituciones y el Estado se desenvuelven cotidianamente (CONETS, 2015, p. 22).

De ahí que la defensa de los Derechos Humanos y la justicia social sean elementos fundamentales para el Trabajo Social en el proceso de lectura de contexto; así el Trabajo Social.

Se posiciona a favor da equidade e da justiça social, na perspectiva da universalização do acesso a bens e a serviços relativos às políticas e programas sociais; a ampliação e a consolidação da cidadania são explicitamente postas como garantia dos direitos civis, políticos e sociais das classes trabalhadoras (NETTO, 2006, p.16).

Partiendo de que el Trabajo social está para garantizar y promover los Derechos Humanos, que trabaja en contra las injusticias y desigualdad social, contra las situaciones de violencia, opresión, pobreza, hambre, y desempleo, se decide apostarle a una metodología transformadora. Es por ello que se trabaja desde la Educación Popular y los postulados de Paulo Freire.

\section{La Educación Popular ${ }^{10}$, más allá de la teoría, una apuesta que es política}

Para Marco Mejía (2013), citado en "Educação popular e pensamento decolonial latinoamericano em Paulo Freire e Orlando Fals Borda" por Mota Neto (2015), la Educación Popular es un acumulado histórico que se hace movimiento y se torna propuesta político-pedagógica. Se caracteriza por su abierta intencionalidad política hacia los intereses del pueblo, sus luchas y objetivos, encaminadas a un proyecto de emancipación social (2015, p. 106).

La Educación Popular no es solo una apuesta profesional, sino también una apuesta de vida. Es una postura que atraviesa, cuestiona, reta, desafía y reivindica la profesión y la vida de cada sujeto que decide asumirla; la Educación Popular es aportar a construir desde el amor, la escucha y la palabra. De ahí que la obra de Paulo Freire no sea solo para pedagogos(as), sino para todos los seres humanos oprimidos(as) que viven la injusticia, y optan por actuar en relación a ella.

A educação popular é ao mesmo tempo um movimento (uma prática, uma experiência, um processo de luta) e um paradigma (um discurso, uma teoria, uma ideologia), que tem como

\footnotetext{
${ }^{10}$ En este trabajo se hablará de Educación Popular con letras iniciales mayúsculas, porque remiten a trabajos educacionales con perspectiva freiriana y no en el sentido de instrucción pública para todos, otra concepción posible de educación popular (MOTA NETO, 2015).
} 
objetivo, por meio da educação, empoderar as classes populares para que enfrentam diversas modalidades de opressão, lutando assim por uma sociedade solidária e inclusiva (MOTA NETO, 2015, p. 117).

La Educación Popular "Es una manera intencionada de hacer educación desde los intereses de los sectores populares y una forma de contribuir a los procesos de transformación social" (MARIÑO; CENDALES, 2004, p.10). Es esperanza, es vida, es movimiento, es justicia, es sentimiento, es alegría, es fuerza, es amor. La Educación Popular pasa por las vidas de cada persona que la asume, la Educación Popular es una invitación a la transformación y no desde una perspectiva de asistencia, la Educación Popular reconoce el carácter político de cada sujeto(a).

\section{DESCRIPCIÓN METODOLÓGICA}

Las estrategias de la Educación Popular son múltiples y diversas, tienen su eje metodológico en la acción-reflexión-acción, trabajar con ellas permite generar procesos dialógicos con actitudes comprometidas y solidarias en la lucha por la vida digna. A continuación, se expone como la concientización, el objetivo de la Educación Popular y el Trabajo Social, se convierte en el método y punto de diálogo de estos dos campos del conocimiento por medio de la IAP - Investigación-Acción Participativa.

\section{La concientización está en el método}

A nivel conceptual y metodológico se considera que la lectura de realidades o contextualización de los sujetos en el mundo hace parte fundamental de los procesos de investigación o intervención del Trabajo Social. Esta lectura de realidades es un proceso de concientización, en el que el sujeto es capaz de leer y leer-se, para así transformar el mundo.

Este proceso de concientización es importante teniendo en cuenta que la conciencia es la presentación y elaboración del mundo; es la "capacidad que tiene el ser humano de distanciarse de las cosas, para hacerlas presentes, inmediatamente presentes" (FREIRE, 2005, p. 13) ${ }^{11}$ y reflexionar sobre ellas. "Pero ninguno se concientiza separadamente de los demás; la conciencia se constituye como conciencia del mundo [...] " (FREIRE, 2005, p. 15) y conciencia de si. Así, la conciencia es en definitiva conciencia del mundo, con una intrínseca relación entre conquistarse, hacerse más sí mismo, y conquistar el mundo, hacerlo más humano.

El ser humano, al ser sujeto histórico y al estar inmerso en la cultura, el lenguaje, la comunicación y otras relaciones humanas que le permiten tener una conciencia de sí, de su existencia, tiene la posibilidad de pensarse en el tiempo e intervenir(se) en el mundo. No es posible comprender al ser humano fuera de sus relaciones con el mundo, es más, su forma de actuar es en función de cómo se perciba en el mundo. Es por ello que por medio de la participación y el diálogo se le apuesta a problematizar la realidad, y asimismo transformarla (FREIRE, 2005).

Por lo tanto, el método más coherente con la propuesta y apuesta del Trabajo Social y la Educación Popular Freiriana, en la que la participación y construcción desde y para la comunidad es la Investigación-Acción Participativa(IAP) ${ }^{12}$. La IAP fue la metodología expuesta y aplicada durante el proceso, junto con las técnicas: cartografía social y el árbol de problemas, que permitieron hacer una identificación y objetivación de la realidad vivida por las y los idosos de la ILPI.

\section{Investigación-Acción Participativa (IAP): tejiendo desde el Trabajo Social y la Educación Popular}

\footnotetext{
${ }^{11}$ Las referencias tomadas son traducción o interpretación literal del libro "Pedagogia do Oprimido" (2005), Editorial Paz e Terra, de Paulo Freire (en portugués).

${ }^{12}$ En adelante IAP.
} 
Según Ezequiel Ander-Egg (2003), la IAP es una metodología que tiene el propósito expreso de producir profundas transformaciones sociales, incluyendo la promoción de procesos de participación popular, sea en términos de movilización de recursos humanos, o de protagonismos de los sectores populares. Es por ello que esta metodología es de interés en los procesos pedagógicos del NEP, ya que no solo se hace un trabajo de enseñanza sino también se llevan a cabo procesos de investigación e intervención directa con y para la comunidad.

La Investigación-Acción-Participativa supone la simultaneidad del proceso de conocer y de intervenir, e implica la participación de las personas involucradas en el programa de estudio y de acción.

\begin{abstract}
En tanto investigación, se trata de un procedimiento reflexivo, sistemático, controlado y crítico que tiene por finalidad estudiar algún aspecto de la realidad, con una expresa finalidad práctica; en cuanto acción, significa o indica que la forma de realizar el estudio es ya un modo de intervención y que el propósito de la investigación está orientado a la acción, siendo ella a su vez fuente de conocimiento; $y$, por ser participación, es una actividad en cuyo proceso están involucrados tanto los investigadores, como la mismas gentes destinatarias del programa, que ya no son consideradas como simples objetos de investigación, sino como sujetos activos que contribuyen a conocer y transformar la realidad en la que están implicados (ANDER-EGG, 2003, p. 4-5).
\end{abstract}

La IAP se caracteriza por tener principios de diálogo, acción, reflexión, y participación. Calderón y López (2013) exponen: 1) La relación horizontal entre educando(a) y educador(a) en la que se reconoce que cada uno(a) tiene un saber; 2) La Práctica de la conciencia por medio de las reflexiones colectivas; 3) El redescubrimiento del saber popular en el que se reconoce, ordena, valida y potencia el saber acumulado de los colectivos sociales; 4) La acción como elemento central de la formación; 5) La participación activa y crítica en las reflexiones de los actores que permite la posibilidad de actuar como iguales, siendo el educador-investigador(a) uno más del colectivo, que pone su saber al servicio de dicha reflexión (potenciándola y sistematizándola) (CALDERÓN; LÓPEZ, 2013, p.5-6). Estos principios se articulan con los presupuestos del Trabajo Social y la Educación Popular Freiriana que maneja el NEP.

La IAP como método de concientización es el puente en el que se tejen el Trabajo Social y

la Educación Popular. Este puente está fundado en la participación activa de los sujetos, dado que permite la reflexión-acción en el que el sujeto cognoscente es capaz de analizar, cuestionar y así mismo transformar su realidad.

Así, durante el periodo de intervención, las temáticas generadoras fueron identificadas y escogidas por las y los participantes, y a su vez las acciones fueron encaminadas hacia dichas temáticas. Es decir, la participación de los sujetos se evidenció en la identificación de temáticas generadoras y en la problematización de las mismas, ya que estas temáticas hacen parte de su realidad y los ubica como protagonistas.

\title{
Las técnicas
}

Dada la dinámica del grupo se aplicaron la cartografía social y el árbol de problemas como técnicas de participación en las que prima la palabra hablada y el lenguaje no verbal (los dibujos), al registrarlos, socializarlos e interpretarlos se reconoce el valor de los saberes que tienen los sujetos y comunidades al interior de sí.

\section{Cartografía social}

La cartografía social es una herramienta metodológica que por medio de la construcción individual y colectiva de mapas se hace una lectura integral de la realidad rescatando la narración oral y la memoria de un grupo o comunidad. Se pueden enunciar tres tipos de mapas: el eco sistémico-poblacional, que se refiere a relaciones territoriales; el temporal-social, en el que se exploran las tensiones de pasado, 
presente y futuro; y el temático, que configura las problemáticas y las planificaciones concretas (BARRAGÁN GIRALDO, 2016. p.257) ${ }^{13}$.

Se propuso empezar por la cartografía social como metodología de trabajo en ILPI porque permite el diálogo que propone la Educación Popular, y se soporta sobre la noción de territorio ${ }^{14}$.

\section{Árbol de problemas}

En este apartado, se expondrá el Árbol de problemas como una técnica que hace parte de la metodología utilizada en la fase de diagnóstico de los proyectos de intervención en Trabajo social, útil para los escenarios pedagógicos del NEP.

El Trabajo Social se caracteriza por la planeación, ejecución y evaluación de proyectos de intervención e investigación social. Estos proyectos de intervención e investigación social pueden ser orientados por diversas metodologías. En proyectos de inversión social por lo general se aplica el enfoque de marco lógico, ya que este se caracteriza por organizar proyectos de manera sintética mediante objetivos, resultados y actividades. Estos proyectos se caracterizan por tener: los fines y propósitos concretos y verificables; las actividades precisas, planificadas, y conectadas entre sí para lograr el propósito; resultados concretos (los cuales parten de la situación que se busca transformar); los recursos establecidos; el tiempo determinado para su ejecución y las y los responsables para la ejecución de las actividades.

Para ello, el proyecto debe pasar por un ciclo o etapas: la identificación, la formulación, la ejecución-seguimiento y la evaluación. La identificación, es la fase que nos interesa, porque es en ella en la que se identifican los problemas que afectan a la comunidad y así mismo se proponen los objetivos o alternativas de solución.

Sin embargo, como estamos en escenarios de Educación Popular, la rigidez y la "eficacia" de los proyectos sociales con el enfoque del marco lógico no son asertivos en las dinámicas de la Educación Popular del NEP, así que se aplica esta técnica desde la Investigación-Acción Participativa.

El principio básico de la IAP podría resumirse en investigar y conocer la realidad para poder actuar; es decir, estudiar los problemas, las necesidades y los intereses de la población involucrada para así mismo con y desde ellos y ellas buscar la transformación social.

Es por ello que es fundamental reconocer las problemáticas e intereses que vive la población, en un principio se planteó la cartografía social, sin embargo, por la dinámica del grupo de idosos(as), se evidencio que la motivación e iniciativas colectivas eran bajas, y se precisaba de actividades un poco más orientadas y motivadoras. Así que se propone articular la técnica del dibujo y mapeo de las problemáticas (tal como lo sugiere la cartografía social) en la ubicación y clasificación de la técnica del árbol de problemas.

El árbol de problemas es una "técnica participativa que ayuda a desarrollar ideas creativas para identificar el problema y organizar la información recolectada, generando un modelo de relaciones causales que lo explican. Esta técnica facilita la identificación y organización de las causas y consecuencias de un problema[...] El tronco del árbol es el problema central, las raíces son las causas y la copa los efectos. La lógica es que cada problema es consecuencia de los que aparecen debajo de él y, a su vez, es causante de los que están encima, reflejando la interrelación entre causas y efectos” (MARTÍNEZ; FERNÁNDEZ, 2008 p. 2).

\section{Descripción del proceso}

\footnotetext{
${ }^{13}$ En un principio se propuso trabajar la cartografía temporal social, y después la cartografía temática, sin embargo, en la ejecución de las sesiones terminó siendo una mixtura, entre una cartografía histórica y temática.

${ }^{14}$ Entendido como espacio socializado y culturizado en el que convergen la cuestión ambiental, económica, política, cultural, social e histórica de los sujetos. El territorio es definido "como espacio colectivo, compuesto por todo el lugar necesario e indispensable donde hombres y mujeres, jóvenes y adultos, crean y recrean sus vidas [...] espacio de vida donde se garantiza la supervivencia étnica, histórica y cultural” (ESCOBAR, 2014, p. 88). 
El grupo de educadoras populares a cargo del proceso en la ILPI es liderado por dos pedagogas del NEP. Ellas han mantenido el quehacer pedagógico en la institución y apoyaron activamente la co-construcción del proceso durante la pasantía de Trabajo Social. En este tiempo se desarrollaron siete encuentros en los que, a medida que se reconocía el grupo y sus intereses individuales y colectivos, se iban desarrollando propuestas de participación y diálogo de forma conjunta con las educadoras, las y los idosos.

\section{Reconocimiento e identificación}

En la primera y segunda ${ }^{15}$ sesión se hizo un ejercicio de observación, escucha, reconocimiento e identificación. Durante la primera sesión las educadoras dirigieron la actividad de presentación y conocimiento del grupo. En busca de lograr horizontalidad, se optó por participar junto con los idosos(as) en la misma actividad. Esto logró que las y los participantes conocieran mejor también a las educadoras.

Con esta observación se evidencia que el ánimo de las y los idosos baja con el tiempo y la participación no es activa, no todos los(as) presentes son partícipes en las actividades. Se identificó que es un grupo que se caracteriza por cansarse rápido y hablar de forma individual, no hay una escucha colectiva, cada participante habla para las educadoras de forma individual y la participación de ellas y ellos hacia el grupo ${ }^{16}$ es restringida.

\section{Cartografía Social: Belém en el pasado}

Se indicó la elaboración individual y colectiva de un mapa de Belém en tiempo pasado. Allí se propuso al grupo la elaboración individual del barrio o los lugares en los que desenvolvieron su vida, y después, se les indico construir el mapa de Belém de forma colectiva. La instrucción individual la entendieron y ejecutaron, sin embargo la participación no fue muy activa en el momento del mapa colectivo, casi no hablaban cuando se le preguntaba en público; al final, en el diseño del mapa colectivo optaron por dibujar de forma individual sin conseguir elaborar una obra común.

Durante el momento colectivo se trató de incentivar al grupo para que dibujaran de forma libre, pero no se consiguió; ellos y ellas están acostumbrados a un trabajo con instrucciones simples y mecánicas. Así que para las siguientes sesiones la metodología tuvo que ser modificada, de forma tal que las instrucciones fueran de fácil entendimiento con una invitación al pensar y reflexionar sus realidades.

De esta sesión se rescatan dos sucesos importantes: el primero, las educadoras llegaron una hora antes de ejecutar la actividad con el fin de preparar el espacio de la maloca, y encontraron que ya el señor Manuel estaba en ella esperando. "El señor Manuel mostró la Carta del Estatuto do Idoso en la que se prevén sus derechos. Y mientras se organizaban las mesas de trabajo se tuvo una conversación sobre la importancia de conocer los derechos"17. Este dialogo fue valioso porque evidencia el interés del señor Manuel en las actividades y la intención de las mismas, al identificar en el NEP la relevancia de los Derechos Humanos y la importancia de reconocerlos(as) como sujetos(as) de derechos.

El segundo, la importancia del territorio en la constitución de las vidas de cada idoso(a) "los y las participantes de la experiencia recuerdan los lugares de trabajo, unos evocan sus lugares de nacimiento, los lugares en que trabajaban... uno de ellos trabajaba en la avenida Nazaré, otros en el mercado, en los terminales rodoviarios; también recordaban el río, la playa, los campos de futbol, sus casa y las personas que hacían parte de estos lugares, las mujeres, abuelas, los pescadores" (NEP, 2018)

\footnotetext{
${ }^{15}$ De los siete encuentros, seis desarrollaron actividades concretas dentro de la institución. El segundo encuentro fue en el Parque Estadual do Utinga, en Belém, y más allá de ejecutar alguna actividad se llevó un ejercicio de escucha y diálogo con las y los idosos durante la caminata por el parque. Esto, como continuación del ejercicio de reconocimiento e identificación poblacional.

${ }^{16}$ Esto hace referencia a que las y los idosos prefieren hablar hacia las educadoras, y cuando se solicita hablar a todo el grupo la participación disminuye.

17 Tomado de las relatorías de las actividades (NEP, 2018).
} 
(ver figura 1). La importancia de los lugares no es constituida sólo por el espacio físico, sino también las personas, y elementos particulares que lo caracterizan; los territorios están constituidos por una red de entramados de relaciones, significados, situaciones cargados de historias, emociones y vida. Ver figura $1^{18}$.

El señor Manuel ${ }^{19}$ habló sobre lo que dibujo, el educando dibujó un barco y una casa, cuando la educadora le pregunto que representaba este dibujo, el explico que representaba todo lo que él ya hizo y los lugares a los que viajo; su dibujo - dice - remite los momentos felices de su vida, cuando trabajaba en las embarcaciones y el trabajo que le proporcionaba el sustento de la familia y que hoy le causa mucha saudades. El señor Manuel ama hablar sobre sus viajes y siempre se reconoce como marinero-en tiempo presente. (NEP, 2018, p. 4).

Figura 1- Diseños de las y los Idosos (17/04/2018)

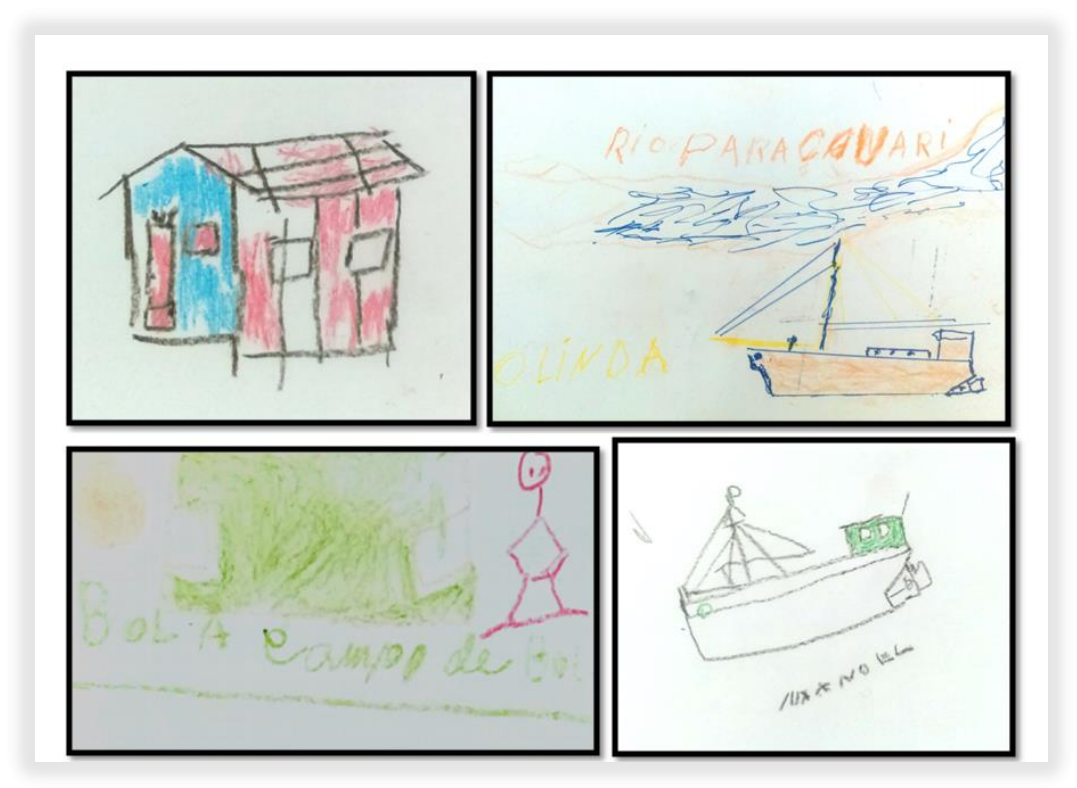

Fuente: NEP (2018)

\section{Cartografía social: pasado-presente}

En el primer momento de esta sesión se decide retomar la cartografía social en pasado con el fin de profundizar un poco más en la temática de los lugares que constituyeron el pasado de las y los idosos de la ILPI. Se propuso recordar el dibujo que ellos y ellas diseñaron, y se provocó la participación con preguntas acerca de los mismos diseños.

Dado que las y los idosos no tenían la misma participación para hablar en público que con las educadoras, se decide escuchar de forma individualizada a cada participante, y después las educadoras socializaron rápidamente que hablo cada uno(a), volviendo a orientar las preguntas y dándole la palabra y el protagonismo a cada idoso(a). Esta propuesta fue acertada, porque ellas y ellos empezaron a hablar con más fluidez, sin embargo se problematizó que la atención solo se obtenía cuando hablaba alguna educadora y no cuando alguno o alguna idosa participaba, así que se le propuso al grupo como reto escuchar a los demás con la misma atención.

En un segundo momento se les indica hacer el mapa del presente, de los lugares que actualmente a ellos les gusta, se delimitó la instrucción a los lugares de la institución, teniendo en cuenta que es el espacio que habitan en la actualidad, allí la mayoría de ellos dibujó la maloca, escenario en el que se desarrollan las actividades, y manifestaron que les gusta porque "aquí nosotros tomamos un airecito,

\footnotetext{
${ }^{18} \mathrm{El}$ diseño del señor Manuel es el del recuadro inferior derecho.

${ }^{19}$ Los nombres aquí presentados son nombres ficticios, seudónimos, por cuidado éticos. Educação em Revista|Belo Horizonte|v.37|e233148|2021
} 
conversamos y hacemos actividades que nos distraen”, “ aquí oímos música y hacemos actividades, es una forma de salir del ruido del salón principal da casa. Aunque todos los lugares de aquí son buenos, las personas son buenas y somos bien tratados aquí", el señor Manuel dibujó el techo de la maloca, rescató que esa era una estructura indígena-circular- y a el le gustaba ello (ver figura 2), también dibujaron lugares de interacción como la sala de televisión y el comedor. La educanda Josefa expresa su interés en la comida y el placer del "refeitório" en el que comen, ven televisión y conversan, expresa que le gusta el açaí con tapioca, y con mucha emoción-abriendo los ojos y saboreando los labios- recuerda el dulce de cupuaçu con pan, la farinha, y la tapioca con queso y mantequilla. (NEP, 2018).

Figura 2: Diseño de la Maloca

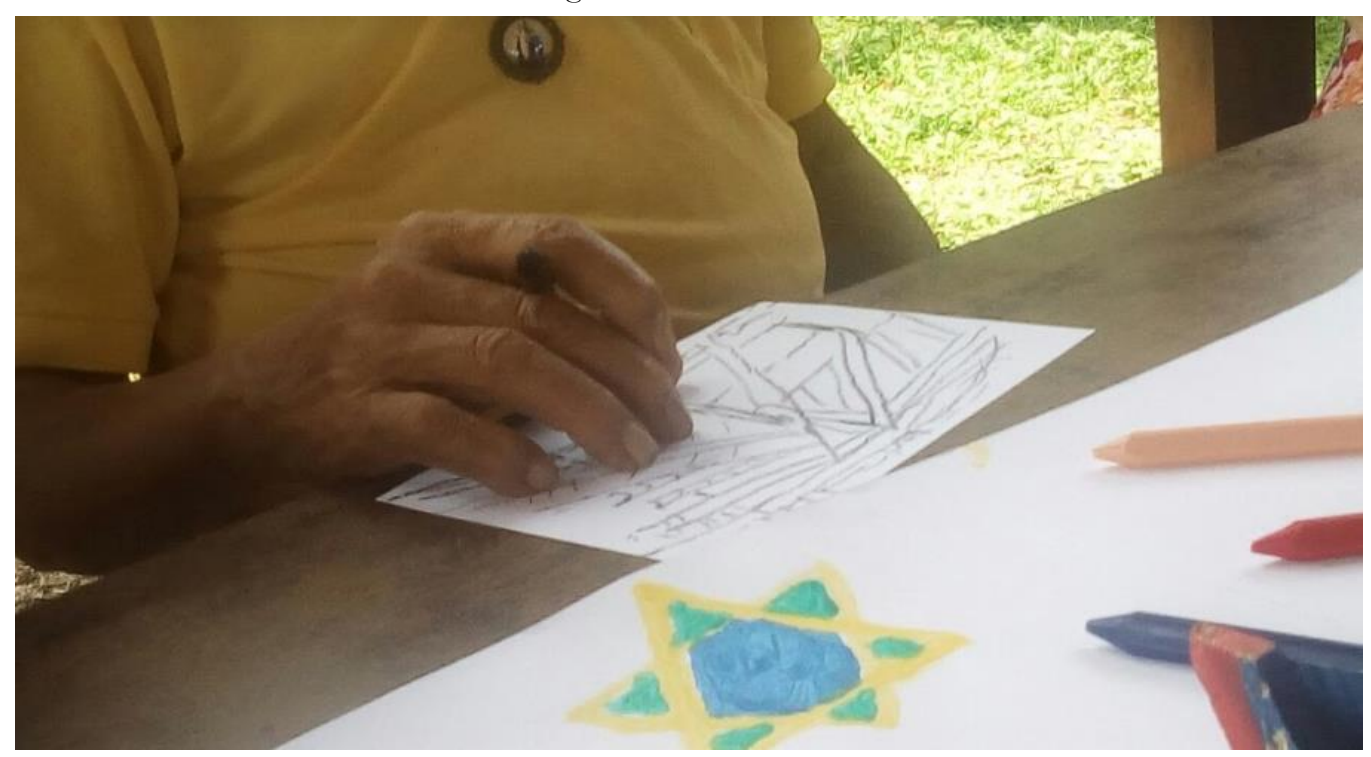

Fuente: NEP (2018)

La cartografía social fue útil para identificar realidades objetivas y subjetivas de cada idoso(a) y del grupo en relación con las temáticas tratadas. Por ejemplo, cuando se habló de lo que les gusta y lo que no, se llegó al tema de la comida; cuando "la señora Antonia dibuja un plato de arroz, frijol, fariña y agua, dijo que eso no le gusta porque es lo que siempre come cuando no tiene dinero, eso es todo los que hay para comer" (NEP, 2018, p. 3). Exponiendo así lo difícil que fue su situación económica y su relación con los alimentos.

La señora Antonia hace referencia a calidad de la alimentación como algo importante, se evidencia que el alimento es algo transversal en las y los idosos, no sólo en el pasado, por los alimentos propios de la región (como el açaí y el pescado) a los que ya no tienen acceso, y que son fundamentales en la constitución de su identidad territorial como paraense ${ }^{20}$, sino también la problematización de la calidad de la alimentación, en el pasado, cuando por diversas razones sociales y económicas no se tenía acceso a la alimentación de calidad, y solo se comía agua, arroz, frijol y fariña, y ahora, cuando su desayuno es siempre "bananada" y no tienen acceso al açaí de forma "libre".

${ }^{20}$ Persona del estado de Pará. 
La cartografía social invitó a pensar en las formas en que podemos descolonizar los campos del saber instituidos hegemónicamente, para así constituir subjetividad. (BARRAGÁN GIRALDO, 2016, p. 259). Por ejemplo, durante las sesiones de cartografía social, el señor Manoel, el señor Olinda, y el señor José se caracterizaron por diseñar constantemente los barcos, como elementos en común, y como un elemento que "representa la vida", ya que como dice el señor Manuel "representaba todo lo que ya hice y los lugares a los que viajé" (ver figura 3). Así las cosas se plantea el barco como un territorio común, para las personas que trabajaron en ellos durante su vida, pero también para el resto de los participantes, que tenían en su paisaje las embarcaciones, por ser un medio de transporte importante en Belém, o porque muchas veces las dinámicas económicas familiares estaban envueltas a las dinámicas de las embarcaciones ${ }^{21}$.

Figura 3-Cartografia

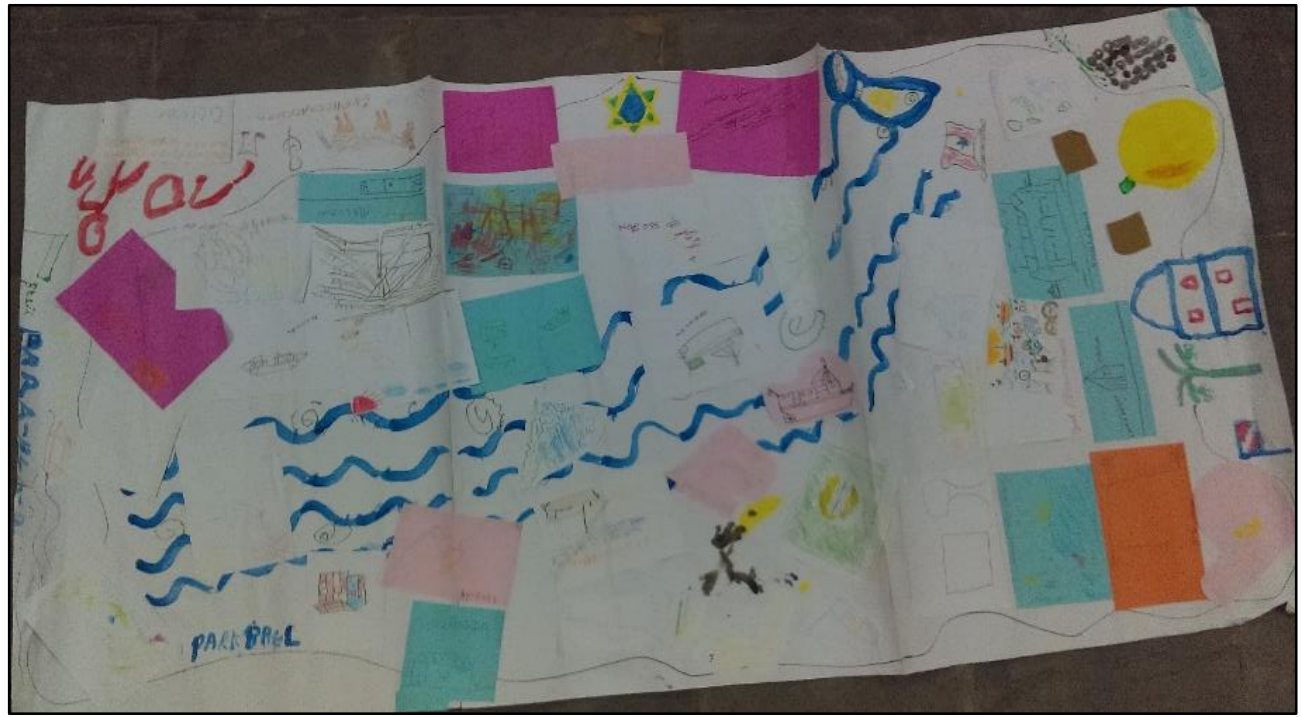

Fuente: NEP (2018)

En un principio se buscó que este ejercicio de cartografía social, tuviera una carga histórica, con el fin de ubicar a los y las participantes como sujetos históricos, activos en su propia realidad. Sin embargo por las propias dinámicas de grupo ${ }^{22}$ no se logró la participación y el trabajo colectivo que se esperaba en relación a la problematización de lo territorial, así que se continuó el desarrollo de la cartografía como técnica y se propuso trabajar el Árbol de problemas desde la Investigación-Acción Participativa como metodología, con el fin de identificar las palabras y temáticas generadoras, insumo para el proceso de trabajo durante el resto del año.

\section{Cartografía social presente - árbol de problemas}

Esta sesión fue importante porque se logró un trabajo real de escucha colectiva, todos(as) quedaron en silencio y realmente escucharon lo que sus compañeros(as) hablaban, por lo general - como se relató en los primeros encuentros - primaban un silencio colectivo cuando las educadoras solicitaban la palabra al grupo, o todos hablaban y ninguno se escuchaba. En esta ocasión se quedaron escuchando y empezaron a hablar respetando la palabra del otro.

\footnotetext{
${ }^{21} \mathrm{~A}$ partir de allí se sugirió tomar el barco, (los puertos, las embarcaciones) como tema generador o elemento de análisis con el cual se puede construir conocimiento desde ellos y para ellos, no solo como una estrategia de memoria sino también como elemento articulador con el trabajo y el territorio, en tanto que Belém se caracteriza por un agitado movimiento marítimo. ${ }^{22}$ Es un grupo que se caracteriza por tener relaciones distantes entre cada uno de los miembros.
} 
Figura 4- Diseño S.r. Manuel

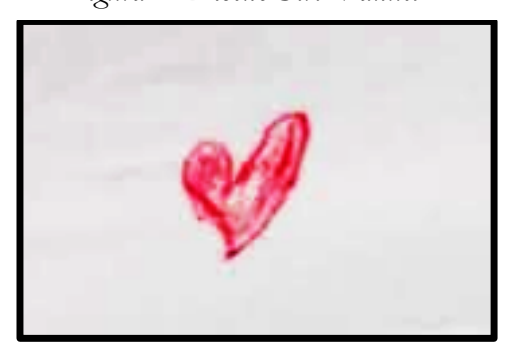

Fuente: NEP (2018)

También fue significativo porque el reto de la primera sesión de cartografía, en la que todos los presentes en la actividades fueran sujetos activos y participativos con la misma, ese día se logró porque participaron activamente; cuando el señor Manuel identificó el tema generador(figura 4): la salud como problema $^{23}$, la señora Josefa, también dijo “yo también tengo problema de diabetes", y la señora Filo, también dijo, que ella tenía problemas de diabetes, la señora María dijo que ella no tenía diabetes pero sí tensión alta, ahí todos empezaron hablar de sus dolencias físicas (NEP, 2018).

Cuando se empezó a provocar la conversación preguntando las causas de una mala salud, o de lo que significa estar enfermo, ellos hicieron énfasis en el cuidado, y en las consecuencias, profundizaron en los dolores que van más allá del cuerpo, y de la importancia de la familia y amigos (redes de apoyo) en situaciones de dolor.

Después de ubicar la salud como tema central, los y las participantes reconocen como causas: falta de saneamiento básico, refriéndose a la basura en la calle, el agua potable, la falta de medicamentos, estilo de vida sedentario, lluvia, mala alimentación... y como consecuencias ellos afirman que no tener salud "é tudo ruim" hay malestar, hay dolor no solo en el cuerpo sino dolor en el alma, hay una atmosfera de tristeza y sufrimiento en la persona y en la familia, hay mucho estrés y se tiene que estar buscando una cura (NEP, 2018, p. 4).

Por medio de la cartografía social y el árbol de problemas se evidenciaron problemáticas vividas individual y colectivamente en las y los idosos; también mencionaron la violencia como una temática importante y aunque las y los idosos no sintieran de forma "directa" la violencia que transmitían los noticieros de la ciudad, ellas y ellos están al tanto de lo que acontece, y ese día problematizaron diferentes tipos de violencia: se habló de la violencia de género "la Sra. Brandão dibujo una niña y expuso la violencia física, el abuso y el trabajo infantil (especialmente el trabajo infantil doméstico en las niñas) ${ }^{24}$, [...] La señora Filomena enfatizo la violencia y el peligro que corren las personas ciegas al estar solas en la calle”. Esto evidencia cómo cada persona hablaba desde su locus de enunciación, en este caso se habló como mujeres, y como personas en discapacidad. Lo interesante de esta sesión, fue que los(as) mismos(as) participantes, llegaron al consenso de la salud, como un tema que los afecta a todos y todas. Y reconocieron como muchas de las problemáticas que experienciaban individualmente, también eran vivencias colectivas.

\section{Árbol de problemas - objetivos}

En esta sesión se ejecutó una actividad de sensibilización, previa al árbol de objetivos. Se les indico cerrar los ojos y escuchar la canción "Eu só peço a Deus" de Mercedes Sosa y Beth Carvalho, una canción que invita a la reflexión y también a la acción. Después de este momento, se les solicitó diseñar

\footnotetext{
${ }^{23}$ Ese momento fue significativo porque el señor Manuel diseño un corazón y la instrucción, fue dibujar lo que consideran problemático, cuando preguntamos porque dibujó un corazón responde, que él sufre del corazón, tiene problemas de tensión y de diabetes. El hecho que él dibujara un corazón, despertó la curiosidad de todos(as) los participantes (Ver figura 4).

${ }^{24} \mathrm{El}$ trabajo infantil doméstico es un fenómeno, muy frecuente aquí en Pará, y consiste en que las NIÑAS, salen de su casa desde muy pequeñas a trabajar en casas de familias de la ciudad, este fenómeno conlleva a que las niñas se expongan a una vulnerabilidad mayor y puedan sufrir abusos y violencias de todo tipo.
} 
o escribir una carta a alguien del futuro, en el que les informara, que es lo realmente importante, que es lo que se debe cuidar y mantener en el tiempo. A esto, los participantes respondieron: "es importante salir para trabajar, ganar dinero", "salud, buen hogar, felicidad, pan, vida, los paseos, la nevera llena de comida", "salud, estar libre de diabetes, presión alta" (aquí, igual que la sesión anterior, varias personas manifestaron también tener diabetes y otras personas tensión alta, hipertensión) "ayudar a vivir bien" "jugar, el sol, porque nos da vida y seca la ropa, la comida, y Pará (lugar en el que vivo, en el que nacî)" "las embarcaciones, son todo lo que yo hacía" "el barco representa la vida" "Dios es importante para mí porque me ayuda a vivir bien" "alguien del futuro, cuide del prójimo" (NEP, 2018).

En este punto se socializó lo importante que era el aporte de cada uno y cada una de ellas, y al final, se llegó a la conclusión de que la salud es uno de los temas en común para el bienestar humano, y que, aunque las cartas se hayan elaborado de manera individual hay elementos en común como la importancia de los alimentos y del trabajo en la vida de todos(as).

Se retoma la sesión del árbol, y se problematiza aún más la cuestión de la salud. Durante las conversaciones surge la temática del trabajo y el trabajo infantil. Se habló de la relación entre salud y vejez, en el que la vejez es problemática por su estrecho vínculo con la salud, sin embargo, también es atravesado por una cuestión de clase, porque como dijo uno de los participantes "los pobres son los que mueren haciendo filas en los hospitales". Se le preguntó quién de ellos trabajaron cuando eran niños(as) y todos asintieron con un sonido seco y un leve movimiento de cabeza, las señoras Filomena y María alzan las manos y relatan que tenían que cargar ropa y lavar las ropas de otras personas, el señor Edimarino manifestó que tenía que cargar ropa desde la Pedreira hasta Ver-o-peso ${ }^{25}$ (Aproximadamente $5 \mathrm{KM}$ ), varias veces al día y que llegaba cansado.

Para cerrar esta sesión, se les indico proponer posibles soluciones a todas las problemáticas que habían enunciado, a esto respondieron: tomar remedio, alimentarse bien, dormir, levantarse temprano, tomar el viento de la mañana, hacer educación física, caminar, regar plantas, y tener una buena relación con Dios (espiritualidad) son acciones necesarias para una buena salud (NEP, 2018).

\section{Despedida y cierre del proceso}

Debido a que el tiempo de la estancia académica terminó se realizó un cierre cultural, con música y comida tradicional: açaí con tapioca ${ }^{26}$, exponiendo lo trabajado a lo largo de los últimos dos meses: el Trabajo Social, la Educación Popular, la cartografía social, el árbol de problemas y la IAP, como parte de un ejercicio de lectura de realidades, se exhibieron fotografías y material visual resultado del proceso y se invitó a seguir trabajando en la lectura-reflexión y acción de la realidad(ver figura 5).

Se recordó como esos últimos cuidados que mencionaron (de alimentarse bien, dormir, levantarse temprano, tomar el viento de la mañana, caminar, entre otros) son importantes y tienen una relación con el reconocimiento de su territorio, sus dinámicas y el desarrollo de sus vidas, se evocaron las sesiones en las que se habló de las experiencias de trabajo infantil y las posibilidades de cuidado propio que han tenido las y los idosos a lo largo de sus vidas y que tienen ahora. Se propusieron el cuidado de si y de los otros como las posibilidades de ser y hacer del presente, en el que se cuenta con el NEP como aliado.

\footnotetext{
${ }^{25}$ La Pedreira es un barrio de la zona oeste de Belém y Ver-o-Peso es uno de los mercados públicos más antiguos de Brasil, localizado en el barrio Cidade Velha al este de Belém.

${ }^{26} \mathrm{La}$ tapioca es la fécula/harina extraída de la raíz de la yuca, es un alimento de origen indígena muy consumido en la región. Se eligió el açaí con tapioca porque estos alimentos tienen un valor simbólico para las y los idosos, y son considerados como sus alimentos favoritos.
} 
Figura 5. Cartografía, árbol de problemas, y fotografías.

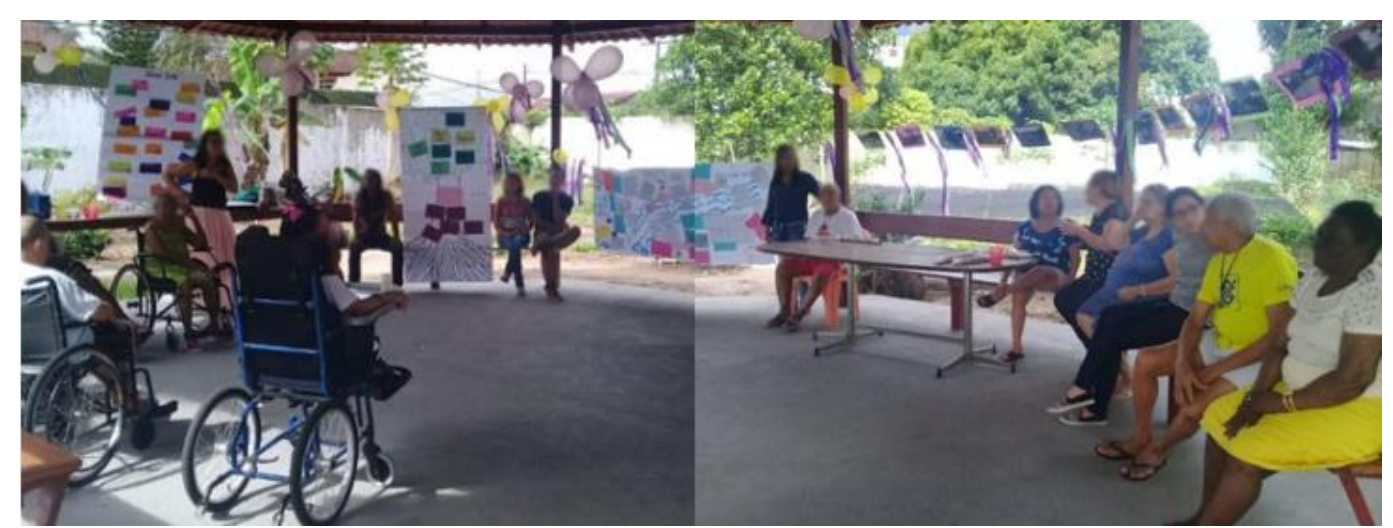

Fonte: NEP (2018)

Después de un momento de música, agradecimiento y conversaciones informales, con los invitados (profesores y participantes del NEP y músicos externos) se decide tocar con guitarra y cantar la canción "só peço a Deus" cerrando así el proceso.

\section{REFLEXIONES SOBRE LA PRÁCTICA}

El principal aporte que se realizó desde la pasantía de Trabajo Social a escenarios pedagógicos del NEP en ILPI es la ejecución de técnicas y metodologías participativas en ejercicio de diagnóstico, contextualización, y lectura de realidades; que dejan como insumo y punto de partida, a nivel conceptual y metodológico, el diseño de proyectos pedagógicos con énfasis en la acción social.

\section{A nivel metodológico}

La cartografía social y el árbol de problemas bajo la IAP son técnicas de participación útiles para los procesos de diagnóstico y lectura de realidad en los grupos de trabajo, bajo una mirada crítica de educación popular. Con el grupo de idosos(as) de la ILPI fueron exitosas estas técnicas dado que existía un interés manifiesto en dialogar acerca de su territorio, sus historias de vida y sus experiencias individuales y colectivas, en el pasado y en el presente. A continuación, se exponen brevemente los principales aportes de dichas técnicas en este proceso.

\section{La cartografía}

La cartografía se planteó como medio para recuperar la palabra, es una técnica que permitió articular los saberes y las actividades ya desarrolladas en la ILPI y plantear el territorio y sus dinámicas como eje problematizador y temático. Con la cartografía se visualizaron y localizaron conflictos, como por ejemplo el alimento, se identificaron patrones identitarios de la población como los frutos y el río, y se denunciaron situaciones como lo fue los diferentes tipos de violencia.

Se consideró que el territorio es un tema generador en tanto que contiene elementos que construyen subjetividad. El territorio es una construcción social que se desarrolla a partir de las significaciones y usos que los sujetos construyen cotidianamente, a partir de historias comunes, usos y sentidos (FERNANDO; GIRALDO, 2016). Como se evidenció en la primera sesión de cartografía social, cuando se habló de Belém (Pará), se habló de elementos constitutivos de la ciudad, el Estado e incluso del país como lo es el mango, el açaí y la tapioca, elementos que han sido y son parte de su historia de vida.

La cartografía social permitió reconocer acontecimientos que subsisten en la memoria del grupo, y llevó a comprender el presente y dibujar posibilidades futuras de actuación. 
Se propuso la técnica del Árbol de problemas para ubicar y organizar los problemas identificados por las y los idosos, y así mismo proponer un proyecto pedagógico de investigación-acción para el resto del año. Es por ello que se exponen las siguientes palabras generadoras, resultado de la clasificación de los problemas y las necesidades que las y los idosos estimaron oportuno analizar para encontrar luego soluciones a esa problemática. Esta tarea se va realizando a partir de cuestiones puntuales y vivencias inmediatas que presenta la población y de manera simultánea se recogió y ordenó junto con ellos y ellas en el árbol de problemas.

Uno de los aportes más importantes del Trabajo Social (y de las pedagogas) es el de sistematizar y devolver a las personas las experiencias problemáticas contextualizadas, evidenciando que no existen necesidades, problemas e intereses individuales y abstractos, sino que están todos directa o indirectamente relacionadas ${ }^{27}$. También con esta técnica se permitió sistematizar los problemas en temáticas generadoras, y a su vez se ubicó a sujetos como parte activa de este tejido de relaciones, ubicándolos así como sujetos participantes y transformadores de su propia realidad. Además, cabe resaltar que la metodología (IAP) permitió experiencias significativas que resultaron del proceso como apuesta de una pedagogía hacia lo humano.

\section{Hacia la pedagogía de lo humano}

Decir que se logró un ejercicio de concientización es algo atrevido para el poco tiempo que se compartió con las y los idosos. Sin embargo, teniendo en cuenta que "la concientización es la inserción crítica de los oprimidos en la realidad opresora, y al objetivar esta realidad, los sujetos pueden actuar sobre ella" (FREIRE, 2005, p. 42) se puede afirmar que por medio de la cartografía social y el árbol de problemas se hizo un ejercicio de inserción crítica en la realidad, que es apenas el primer paso para una pedagogía crítica.

La pedagogía que propone Paulo Freire como pedagogía de lo humano, tiene dos momentos distintos: el primero, en que los sujetos(as) van desvelando el mundo de la opresión y van comprometiéndose en la praxis con su transformación, por medio de una lectura crítica de la realidad; y el segundo, en el que los sujetos expulsan los mitos creados y desarrollados en la estructura opresora (FREIRE, 2005). Durante el proceso con las y los idosos se logra este primer momento de lectura y análisis crítico de la realidad.

Durante el desarrollo de las actividades, surgieron varios momentos emotivos y de reflexión individual y colectiva. Teniendo en cuenta que "El lugar de encuentro y de reconocimiento de las conciencias, también es del encuentro y del reconocimiento de sí mismos" (FREIRE, 2005, p. 20). Es de resaltar dos momentos importantes: cuando se habló de trabajo infantil y cuidado del otro.

Cuando, se les preguntó quién de ellos trabajo cuando eran niños(as) y todos asintieron con un sonido seco y un leve movimiento de cabeza. La señora Filomena y María alzaron la mano y relataron que tenían que cargar ropa y lavar las ropas de otras personas, el señor Edimario provoco un debate en relación a la sociedad capitalista y la lucha de clase, el destacó que "el pobre no pasa bien, no", explicó porque el trabajo y el dinero son tan importante, el señor Edimario continuó los relatos, explicando que trabajaba desde los 9 años, él ayudaba a su madre cargando bandejas de ropa en la cabeza, mentía a su madre diciendo que iría para la escuela, mientras tanto estaba trabajando como vendedor en el Mercado do Ver-o-Peso. Ese día varias personas empezaron a narrar sus infancias atravesadas por el trabajo, la escasez, el abandono e incluso la mendicidad, ese día el grupo se sumergió en una nostalgia colectiva, ese día se recordaron unas infancias heridas...el grupo provocó y respetó un silencio profundo, y con una voz de esperanza la señora Josefa cierra el espacio "pero eso ahora es prohibido, ahora los niños deben ir a la escuela".

${ }^{27}$ Esta también es la razón de ser de este texto.

Educação em Revista|Belo Horizonte|v.37|e233148|2021 
El segundo momento de reflexión profunda que se sintió en el grupo fue cuando en el árbol de problemas-objetivos se les indico diseñar y escribir una carta "para alguien del futuro", indicando que era lo importante en el pasado, actualmente y que se deba preservar en el tiempo, la señora Rosinha en su diseño dice, que para ella es importante "cuidar del prójimo", ahí, se les pregunta a todos que si eso es importante o no. A esto todos responden que sí, inmediatamente, se les pregunta si ¿ellos(as) cuidan de los otros(as)? ¿de sus colegas?. El grupo reacciona con varias miradas al piso y entre dientes una respuesta negativa. Se respeta el silencio del grupo y se hace la invitación a construir en su presente todo lo que para ellos fue, es y será importante.

Se busca que el educador(a) y el educando(a) establezcan una forma auténtica de pensar y actuar, pensarse a sí mismos y al mundo, simultáneamente, sin dicotomizar este pensar de la acción (FREIRE, 2005). A partir de las relaciones reconocidas por los idosos en la cartografía social y el árbol de problemas, se logró identificar las relaciones (con él árbol de problemas) y las significaciones (con la cartografía social) de los elementos constitutivos de sí, como personas y como grupo. Estas técnicas permiten problematizar y resignificar los elementos y situaciones significativos y constitutivos de las personas, a partir de un ejercicio de reflexión crítica de la realidad.

Se afirma que el grupo logro la inserción critica en la realidad, en tanto estas técnicas permitieron que las y los idosos analizaran como sus historias de vidas, y sus experiencias respondían a un contexto histórico especifico con determinadas dinámicas socio-culturales, que han permitido que sus vidas pasen por una matriz de opresión atravesada por la pobreza, en este caso.

En la cartografía la señora Antonia relató que su casa era de barro, muy humilde; el señor Manuel señala su casa en palafita, y mientras Antonia habla sobre las necesidades económicas que vivió su familia, las miradas y la escucha se volvieron empáticas, recordando su propia experiencia.

\footnotetext{
O senhor Edimarino assinalou o desrespeito ao idoso e à educação autoritária, destacando que "Pobre não passa bem, não". Além disso, explicou que o trabalho é tão importante, "porque ele que dá o dinheiro" e tudo seria diferente com ou sem dinheiro. A educanda Filomena, por sua vez, traz a discussão da luta de classes, afirmando que o "Pobre é humilhado; eles [os políticos] só fazem o que eles querem. É difícil mudar a cabeça dos outros. É necessário que todo mundo mude. Nem todos, umas pessoas mudam, outras não, tem pessoas arrogantes, que se acham melhor" (NEP, 2018, p. 8).
}

Se retomó la discusión cuando se trabajó con el árbol de problemas - objetivos. En ese día se les solicitó que propusieran soluciones a los problemas identificados a lo largo de los encuentros, principalmente la salud; sin embargo, no se veían muy participativos. Por ello se optó por hablar de Paulo Freire y la importancia de leer el mundo para la lectura y transformación de la realidad. Frente a esto, uno de ellos plantea que "não sabia ler, e é por isso que eu era e sou burro. Não ia estudar porque ia para o Ver-o-Peso trabalhar, para ganhar um trocado. Um dia minha mãe me viu, e ela me disse que por isso que não aprendi e não aprenderia, se quisesse ficar assim toda a minha vida" (NEP, 2018, p. 9).

El dialogo no se redujo al acto de leer libros o palabras escritas, sino que se direccionó a la lectura como parte de un ejercicio de una lectura crítica del mundo, de la realidad. Se expuso un pequeño relato en el que la lectura es resignificada. Este relato fue basado en una observación camino al ILPI: dos niños de 7 y 9 años aproximadamente, muy temprano caminando las calles de Belém, recogiendo los mangos para luego venderlos. Tras recordar sus propias infancias se invitó a pensar en los niños y niñas que trabajan desde pequeños en la calle, se les preguntó si ¿estos niños y niñas saben lo que significa trabajar?, ¿obtener dinero?, ¿'sabrán ellos como trabajar para traer comida a casa? y ¿ será que ellos y ellas no saben cómo es la vida?. Las y los idosos respondieron que sí; aquí se les planteó que así como los niños y niñas que trabajan desde muy jóvenes entienden como "funciona" el mundo, un mundo precarizado, en el que tienen que trabajar para obtener comida; así también es necesario que las personas entiendan que tienen que hacer para sobre llevar una vida digna, pero parte de esta pedagogía no es meramente entender "cómo funciona el mundo", sino al contrario problematizarlo, problematizar las propias experiencias, verlas, describirlas, analizarlas para así transformarlas; es a esto a lo que se le apuesta 
desde la Educación Popular. Y por ello se problematizaron las propias experiencias de vida que al principio parecían individuales, y al final terminaron siendo experiencias comunes.

Se logró una inserción crítica en la realidad al descubrir, así como afirman Freire y Betto (1994), que no existe crisis personal, sino que existen maneras personales de sentir crisis colectivas. Las y los idosos reconocieron que aunque cada uno vivió sus vidas independientemente, sus historias de vida están marcadas por experiencias de opresión en común de pobreza, abandono, el trabajo infantil y la salud, deteriorada en parte por la imposibilidad de un cuidado a la vida y el cuerpo propio. Ahora bien, este análisis permitió surgir reflexiones en torno al presente y las posibilidades de acción de los idosos en torno al autocuidado y el cuidado de los otros y otras. Durante las conversaciones se evidenciaba como las y los idosos se asumían como sujetos demandantes de cuidado; a partir de estos diálogos se les propuso en su cotidianidad en el ILPI, ser cuidadores de si, de los otros (escuchar, compartir y conversar con el colega) y de lo otro (las plantas, el hogar mismo) como una apuesta política.

Respecto a la participación de los idosos(as), se planteó la motivación como reto y se cuestionó como equipo de trabajo la motivación de los idosos. En ocasiones - particualrmente al inicio las y los idosos se mostraban poco participativos o justificaban su pasividad en un "no saber". En la cartografía, por ejemplo, la señora Maria, en un momento, se mostró insegura en empezar a diseñar el mapa y decía que no sabía pintar; después al momento colectivo, varios participantes respondían que no sabían dibujar un mapa, aun cuando ya habían adelantado su diseño individual. ¿Porque ellos no se atreven a participar? ¿Cómo podemos despertar la curiosidad?” Ante esto, Freire (2005, p. 55-56) afirma que:

Este fatalismo, alongado em docilidade, é fruto de uma situação histórica e sociológica e não um traço essencial da forma de ser do povo [...] a autodesvalia é outra característica dos oprimidos resulta da introjeção que fazem eles da visão que deles têm os opressores. De tanto ouvirem de si mesmos que são incapazes, que não sabem nada, que são enfermos, tudo isto termina por convencer de sua "incapacidade".

Para ello, hay que tener en cuenta que lo que moviliza a la población es la satisfacción de sus necesidades primarias, de sus problemas y de todo aquello que haga a su realización personal, familiar, grupal o comunitaria. Se trata, pues, de identificar las áreas problemáticas y dentro de ellas, identificar los problemas específicos que se quieren y pueden resolver. En este proceso la salud fue el tema movilizador. Es por eso que se plantean las siguientes categorías como palabras y temáticas clave para continuar trabajando con las y los idosos de la ILPI.

\section{A nivel teórico}

Es necesario leer el mundo y entender la realidad para transformarla, con este proceso se apostó por la cartografía social y el árbol de problemas como técnicas participativas en las que se rescata el saber, el interés y las experiencias de las y los idosos y se analiza bajo una perspectiva crítica. Tal como lo plantea Santos (2018, p. 544):

Solo el pasado como opción y como conflicto es capaz de desestabilizar la repetición del presente. Maximizar esa desestabilización, es la razón de ser de un proyecto educativo emancipador. Para eso tiene que ser, por un lado, un proyecto de memoria y de denuncia y, por el otro, un proyecto de comunicación y complicidad.

Lograr que las y los idosos mejoraran su participación en los espacios hablando de sus intereses: sus problemas actuales e históricos se considera como un gran acierto del proceso, además de rescatar las siguientes categorías a partir de los diálogos y análisis de los propios idosos. 
El árbol de problemas permitió identificar por los propios idosos(as) relaciones entre las categorías: Saludy Trabajo como base para una profunda y seria revisión académica ${ }^{28}$. Se inicia con la vejez. como categoría fundamental con el fin de ubicar a los sujetos en el espacio-tiempo que viven actualmente a nivel individual y colectivo. El grupo escogió la salud como temática central por ser una temáticaproblemática que viven todos y todas. Se propone la categoría de trabajo por ser un tema que sin ser planeado (por las educadoras) estuvo presente en casi todas las sesiones y se considera el trabajo como un elemento constitutivo del ser humano. Por último, se propone el género como temática ya que en el grupo hay varias mujeres y muchas de ellas vivenciaron violencia sexual, física y simbólica y tienen resistencia con los hombres.

Producto de la pasantía se pretende proponer las categorías que resultaron del proceso de identificación como un sumario de temáticas a trabajar con perspectivas o metodologías participativas. Siendo esto insumo, para la elaboración conjunta de un proyecto de intervención pedagógica para el futuro.

Así las cosas, a nivel metodológico se sugiere continuar trabajando con la InvestigaciónAcción Participativa que propone Orlando Fals Borda y Paulo Freire, donde la investigación se basa en la acción y la acción se fundamenta con la investigación.

Continuando con la importancia de la lectura de la realidad, se propone trabajar en un primer momento la vejez, como condición en la que se encuentran las y los idosos, y como parte del proceso de comprensión que deben hacer las pedagogas antes, durante y después del trabajo pedagógico.

Vejez, salud, trabajo y genero

Se propone conceptualizar la vejez y a su vez cuestionar el ¿por qué? es problemática (si es que ellos y ellas la asumen como problemática).

Monica de Assis (2005) citando a Ferrari (1999) afirma que: O envelhecimento humano é um processo universal, progressivo e gradual. Trata-se de uma experiência diversificada entre os indivíduos, para a qual concorre uma multiplicidade de fatores de ordem genética, biológica, social, ambiental, psicológica e cultural. Não há uma correspondência linear entre idade cronológica e idade biológica. A variabilidade individual e os ritmos diferenciados de envelhecimento tendem a acentuar-se conforme as oportunidades e constrangimentos vigentes sob dadas condições sociais (p. 2-3).

La vejez es una realidad heterogénea para cada sujeto, pero si se logra encontrar puntos de convergencia entre los factores sociales, ambientales y culturales de cada idoso, se puede construir una concepción colectiva de lo que significa la vejez en la ILPI. Se sugiere iniciar identificando como conciben las y los idosos la relación entre vejez y salud -categoría identificada por ellos-; salud y trabajo ${ }^{29}$ ; vejez y género. Y a partir de allí, se recomienda un trabajo desde una perspectiva interseccional. "La idea de la 'interseccionalidad' pretende capturar las consecuencias estructurales y dinámicas de interacción

\footnotetext{
${ }^{28}$ En una de las sesiones se problematizo esto con las los idosos y se discutió la influencia del trabajo infantil en la salud de las personas idosas de la ILPI y así mismo se propuso como un tema potente para una futura investigación-acción en las causas de sus problemas actuales de salud; por ejemplo, la gran mayoría tiene problemas de diabetes, sería interesante hacer un análisis individual y colectivo de las causas de la diabetes, y si esta se reduce a un tema genético, o también puede estar relacionada con el tema del cuidado en la vida adulta y las posibilidades de cuidar de si en personas con condiciones socioeconómicas precarias (como lo fueron los idosos/as).

${ }^{29}$ Se plantea el trabajo como categoría de análisis, porque estuvo presente en las sesiones como elemento constitutivo de la identidad de las y los idosos en la ILPI. Bajo una perspectiva marxista, el trabajo es la premisa de toda la historia humana, es una categoría económica- antropológica. Marx afirma que el trabajo es la actividad directa del ser humano sobre la naturaleza, y es en el producto del trabajo donde se objetiva la energía del ser humano. Esta objetivación es dada por el reconocimiento del trabajo y del valor del producto por parte de otro. Es decir, el trabajo permite la creación del mundo simbólico; este mundo simbólico se va modificando de acuerdo a la época, sin embargo, los productos que se generen del trabajo van a significar en la subjetivación de la persona, como construcción de la identidad y alteridad (VÁZQUEZ, 1983). 
entre dos o más formas de discriminación o sistemas de subordinación[como de clase, raza, edad, etc]" (UNZUETA, 2010, p. 25).

Se sugiere tener en cuenta: tiempos históricos, culturales, clases sociales, historias personales, condiciones educativas, estilos de vida, géneros, profesiones y etnias, que permitan comprender la vejez como resultado de un tejido de situaciones en permanente interacción con múltiples dimensiones del vivir. "A observação de padrões diferenciados de envelhecimento e a busca por compreender os determinantes da longevidade com qualidade de vida têm motivado estudos na linha de compreensão do que constituiria o bom envelhecer" (ASSIS, 2005, p. 2).

\section{CONSIDERACIONES FINALES}

La pasantía de Trabajo Social en el proceso de Educación Popular con idosos(as) dejó diversos aprendizajes a nivel teórico y metodológico. Uno de vital importancia es la metodología flexible, que se pueda adaptar a las necesidades y deseos del grupo, para así garantizar la apropiación y participación del grupo en el proceso, en este caso se aplicaron dos técnicas en busca de lograr el objetivo de leer y analizar la realidad con carácter crítico y colectivo.

A nivel metodológico, también es de resaltar la escucha entre todos(as) como elemento fundamental en el desarrollo de los procesos educativos. Permitir que las y los participantes tuvieran protagonismo logró que apropiaran el espacio de una forma diferente, esto por ejemplo obtuvo mayor y mejor participación por parte de las y los idosos.

A partir de las relaciones reconocidas por los idosos en la cartografía social y el árbol de problemas, se logró identificar las relaciones (con el árbol de problemas) y las significaciones (con la cartografía social) de los elementos constitutivos de sí, como personas y como grupo.

La salud fue el tema generador, porque el señor Manuel logró simbolizarlo de forma acertada, y además es una problemática que todos las y los idosos viven o han vivido. Cuando analizaron las causas y consecuencias de forma histórica evidenciaron que en muchas ocasiones esos cuidados a los que refieren para una buena salud son parte también de un privilegio y posibilidades económicas/de clase. "O pobre pasa mal" como ellos mismos decían, el coincidir en crecer en condiciones económicas difíciles, el trabajo infantil y violencias sistemáticas sobre los cuerpos de las y los idosos, permitieron entender que hay fenómenos sociales, como el trabajo infantil y la pobreza, que son vividos desde nuestras historias de vida particulares.

Estas técnicas permitieron problematizar y resignificar los elementos y situaciones significativos y constitutivos de las personas, a partir de un ejercicio de reflexión crítica de la realidad. Convirtiendo el proceso en un ejercicio de concientización, en el que el método: la IAP-Investigación Acción Participativa fue el punto de diálogo desde que se tejió de la Educación Popular y el Trabajo Social. Se puede afirmar que por medio de la cartografía social y el árbol de problemas se hizo un ejercicio de inserción crítica en la realidad, que es apenas el primer paso para una pedagogía crítica.

Por último, es preciso señalar que este artículo es resultado de la sistematización y análisis del proceso como muestra de reciprocidad con el grupo del NEP y de las y los idosos de la ILPI. En esta experiencia, devolver a las personas las experiencias problemáticas contextualizadas, permitió comprender que no existen necesidades, problemas e intereses individuales y abstractos, sino que están todos directa o indirectamente relacionadas, es por ello que es necesario un análisis interseccional entre categorías, bajo una perspectiva ética y política clara: la lucha por la vida digna.

\section{REFERENCIAS}

ANDER-EGG, Ezequiel. Repensando la Investigación-Acción Participativa. Buenos Aires: Editorial Distribuidora Lumen SRL, 2003.

ASSIS, Mônica de. Envelhecimento ativo e promoção da saúde: reflexão para as ações educativas com idosos. Revista APS, vol. 8, n. 1, p. 15-24, jan./jun. 2005. 
BRASIL. Estatuto do Idoso. Lei no 10.741, de $1^{\circ}$ de outubro de 2003. Dispõe sobre a Política Nacional do Idoso, e dá outras providências. Diário Oficial da União, Brasília.

CALDERÓN, Javier.; LÓPEZ, Diana. Orlando Fals Borda y la investigación acción participativa: aportes en el proceso de formación para la transformación. Memoria del I Encuentro hacia una Pedagogía Emancipatoria en Nuestra América realizado en el Centro Cultural de la Cooperación Floreal Gorini, 2013.

CONETS. Codigo de Ética para los Trabajadores Sociales en Colombia. Consejo Nacional de Trabajo Social. Ley 53 de 1977. Decreto reglamentario N²833 de 1981. Bogotá, Colombia, 2015.

ESCOBAR, Arturo. Sentipensar con la tierra: Nuevas lecturas sobre desarrollo, territorio y diferencia. Medellín: Ediciones UNAULA, 2014.

FERNANDO, Diego; BARRAGÁN, Giraldo. Cartografía social pedagógica: entre teoría y metodología. Revista Colombiana de Educación, n. 70, p. 247-285, 2016.

FREIRE, Paulo. Pedagogía de la autonomía: saberes necesarios para la práctica educativa. México: Siglo XXI, 2006.

FREIRE, Paulo. Pedagogia do oprimido. 42ed. Rio de Janeiro: Paz e Terra, 2005.

FREIRE, Paulo; BETTO, Frei. Essa escola chamada vida. São Paulo: Ática, 1994.

LEAL, Milene Vasconcelos. Trajetória educativa escolar: memória de idosos. Dissertação (Mestrado em Educação). 118f. Universidade do Estado do Pará, Belém, 2017.

MALAGÓN, Edgar. Trabajo Social: ética y ciencia. Facultad de Ciencias Humanas, Universidad Nacional de Colombia, 2003.

MALAGÓN, Edgar. Fundamentos de Trabajo Social. Facultad de Ciencias Humanas. Universidad Nacional de Colombia, 2012.

MARTÍNEZ, Rodrigo; FERNÁNDEZ, Andrés. Árbol de problemay áreas de intervención. México: CEPAL, 2008. Recuperado el 02 de Mayo de 2018, de :

https://serviciosenlinea.comfama.com/contenidos/servicios/Gerenciasocial/html/Cursos/Cepal/me morias/CEPAL_Arbol_Problema.pdf

MEjÍA, Marco Raúl. Posfácio - La Educación Popular: una construcción colectiva desde el sur y desde abajo. In: STRECK, Danilo; ESTEBAN, Maria Teresa (Orgs.). Educação Popular: Lugar de construção social coletiva. Petrópolis: Vozes, 2013.

MOTA NETO, João Colares da. Educação popular e pensamento decolonial latino-americano em Paulo Freire e Orlando Fals Borda. 368f. Tese (Doutorado em Educação) - Universidade Federal do Pará, Belém, 2015.

MOTA NETO, João Colares da.; OLIVEIRA, Ivanilde Apoluceno de. Contribuições da educação popular à pedagogia social: por uma educação emancipatória na Amazônia. Revista de Educação Popular, v. 16, n. 3, p. 21-35, 2017.

NEP. Relatório das atividades pedagógicas na ILPI. Belém: NEP, 2018.

NETTO, José. Paulo. A construção do Projeto Ético-Político do Serviço Social. In: TEIXEIRA, M. et al (Orgs.) Serviço Social e Saúde: formação e trabalho profissional. 3. ed. São Paulo: Cortez, 2006.

OXFAM. Ocho personas poseen la misma riqueza que la mitad más pobre de la humanidad. 2017. Recuperado el 20 de mayo de 2018, de: https://www.oxfam.org/es/sala-de-prensa/notas-de-prensa/2017-01-

16/ocho-personas-poseen-la-misma-riqueza-que-la-mitad-mas

SANTOS, Boaventura de Sousa. Educación para otro mundo posible. In: SANTOS, B. S. Construyendo las Epistemologías del Sur: para un pensamiento alternativo de alternativas. (vol. 2). Buenos Aires: CLACSO, 2018. 
VÁZQUEZ, Guillermo. Elementos para una interpretación filosófica del joven Marx. Revista Controversia, n.115-6, p. 55-63, 1983.

UNICEF. Estado mundial de la infancia. 2016. Recuperado el 20 de Mayo de 2018 de : https://www.unicef.org/spanish/publications/files/UNICEF_SOWC_2016_Spanish.pdf.

UNIVERSIDAD NACIONAL DE COLOMBIA. Guia para la formulación de proyectos considerando la metodología del Banco de Proyectos de la Universidad Nacional de Colombia (BPUN). Medellín: Centro de Publicaciones Universidad Nacional de Colombia Sede Medellín, 2016.

UNZUETA, María Angeles Barrère. La interseccionalidad como desafío al mainstreaming de género en las políticas públicas. Revista Vasca de Administración Pública, n. 87-88, p. 225-252, 2010.

Submetido: $13 / 02 / 2020$

Aprovado: $27 / 08 / 2020$ 